\title{
Mixture fraction, soot volume fraction, and velocity imaging in the soot- inception region of a turbulent non-premixed jet flame
}

\author{
Okjoo Park, ${ }^{1}$ Ross A. Burns, ${ }^{2}$ Oliver R.H. Buxton, ${ }^{2}$ Noel T. Clemens ${ }^{1}$ \\ ${ }^{I}$ Department of Aerospace and Engineering Mechanics, \\ University of Texas at Austin, Austin, TX 78712, USA \\ ${ }^{2}$ NASA Langley Research Center, Hampton, VA, 23681, USA \\ ${ }^{3}$ Department of Aeronautics, Imperial College, London, UK
}

\section{Corresponding Author:}

Dr. Noel Clemens

Department of Aerospace and Engineering Mechanics, University of Texas at Austin

Austin, Texas 78712, USA

Phone: 512-471-6773

Fax: $512-471-3788$

Email: clemens@mail.utexas.edu

Colloquium Topic Area: Diagnostics

Total length: 6180 words

Main text: 3939 words (MSWord 2010 word count)

Equation: ( 3 equation lines +2 blank lines $) \times(7.6$ words/line $) \times(\#$ columns $)=38$ words

References: $\quad(38$ references +2$) \times(2.3$ line/reference $) \times(7.6$ words $/$ line $)=699$ words

Figure 1: $\quad[49 \mathrm{~mm}+10 \mathrm{~mm}] \times 2.2$ words $/ \mathrm{mm} \times 1$ column +62 words $=192$ words

Figure 2: $\quad[46 \mathrm{~mm}+10 \mathrm{~mm}] \times 2.2$ words $/ \mathrm{mm} \times 2$ column +41 words $=287$ words

Figure 3: $\quad[120 \mathrm{~mm}+10 \mathrm{~mm}] \times 2.2$ words $/ \mathrm{mm} \times 1$ column +65 words $=351$ words

Figure 4: $\quad[42 \mathrm{~mm}+10 \mathrm{~mm}] \times 2.2$ words $/ \mathrm{mm} \times 1$ column +64 words $=180$ words

Figure 5: $\quad[59 \mathrm{~mm}+10 \mathrm{~mm}] \times 2.2$ words $/ \mathrm{mm} \times 1$ column +15 words $=167$ words

Figure 6: $\quad[57 \mathrm{~mm}+10 \mathrm{~mm}] \times 2.2$ words $/ \mathrm{mm} \times 2$ column +31 words $=326$ words

Figure (total): 1503

Submitted for consideration in the Proceedings of the Combustion Institute 


\title{
Mixture fraction, soot volume fraction, and velocity imaging in the soot- inception region of turbulent non-premixed jet flames
}

\author{
Okjoo Park, ${ }^{1}$ Ross A. Burns, ${ }^{2}$ Oliver R. H. Buxton, ${ }^{3}$, Noel T. Clemens ${ }^{1}$ \\ ${ }^{1}$ Department of Aerospace and Engineering Mechanics, \\ University of Texas at Austin, Austin, TX 78712, USA \\ ${ }^{2}$ NASA Langley Research Center, Hampton, VA, 23681, USA \\ ${ }^{3}$ Department of Aeronautics, Imperial College, London, UK
}

\begin{abstract}
An experimental study is performed to investigate the feasibility of conducting simultaneous mixture fraction, soot volume fraction and velocity imaging in sooting jet flames. The measurements are performed in the soot-inception region of ethylene jet flames, where the yellow luminous region first appears in the flame. Three-component velocity and soot volume fraction are measured by stereoscopic particle image velocimetry and laser-induced incandescence, respectively. The mixture fraction is inferred from laser-induced fluorescence of krypton gas seeded into the fuel stream. To obtain mixture fraction from the fluorescence signal, the signal must be corrected for density and fluorescence quenching effects. This correction is accomplished by invoking an assumed state relationship that is derived from a laminar strained-flame calculation. Once properly calibrated, the krypton planar laserinduced fluorescence data give the mixture fraction, temperature and major species near the regions of soot formation. The krypton is seeded into the fuel jet at a mole fraction of approximately $4 \%$. The fluorescence of krypton is achieved by two-photon absorption at $214.7 \mathrm{~nm}$ and the resulting fluorescence is collected at $760.2 \mathrm{~nm}$. The krypton fluorescence signal is rather weak, particularly near the reaction zones where density is lowest, and so adequate signal-to-noise ratios could be achieved in a sheet only about $1 \mathrm{~mm}$ in height, which effectively limited this study to a line measurement of mixture fraction. The temperature field derived from the mixture fraction field was compared to temperatures obtained from thermocouple measurements. The mean radial temperature profiles using the different techniques show excellent agreement and this serves to validate the methodology used to map from fluorescence signal to mixture fraction and temperature. The resulting data are of high enough quality as to allow the investigation of the kinematics, thermo-chemical state and even the dissipation fields near regions of soot formation.
\end{abstract}

\section{Keywords:}

Soot; Turbulent jet flame; LII; PIV; PLIF 


\section{Introduction}

The prediction of soot emission in practical combustors is complicated by the complex interaction between the turbulent flow, chemical reactions, and soot particle dynamics. Several recent studies have investigated the interaction between soot formation and transport both experimentally (e.g., [1-3]) and numerically (e.g., [4-6]), but there remains a need for more comprehensive measurements of soot together with velocity and quantities that describe the thermochemical state of the flow. For example, simulations indicate that soot formation is related to the local mixture fraction $Z$ and its rate of dissipation $\chi$ [7], but such measurements are quite challenging to make in sooting flames and thus have not yet been reported in the literature. Although mixture fraction has not yet been measured in turbulent sooting flames, recent studies have successfully made measurements of temperature and soot volume fraction using simultaneous two-line laser-induced indium fluorescence and laser-induced incandescence (LII) [8]. Furthermore, Burns et al. [9] also reported high accuracy temperature measurements using diode laser excited two-line atomic fluorescence thermometry in low pressure sooting flames. Zhang et al. [10] performed PAH, OH planar laser-induced fluorescence (PLIF) and LII in ethylene and JP-8 piloted jet flames.

To infer $Z$ in sooting non-premixed flames, we apply two-photon krypton PLIF. Two-photon $\mathrm{Kr}$ PLIF is a relatively new technique that has proven useful for making $\mathrm{Z}$ measurements in Sandia target flames [11]. $\mathrm{Kr}$ is a noble gas and is chemically inert in the presence of combustion, and thus its concentration can be related to $\mathrm{Z}$ provided a suitable state relationship is available to account for density and fluorescence quenching effects. In more recent work, the suitability of $\mathrm{Kr}$ PLIF to make $\mathrm{Z}$ measurements in sooting flames was investigated. In Ref. 3, a preliminary study was conducted where $\mathrm{Kr}$ PLIF was applied in the soot inception region of non-premixed ethylene flames. Kr was seeded into the ethylene $\left(\mathrm{C}_{2} \mathrm{H}_{4}\right)$ jet at mole fractions of 4 and 8 percent, and it was shown that PLIF signal profiles 
10 diameters downstream remained undistorted by absorption or stimulated emission effects for the $4 \%$ case [3]. It was demonstrated that the $\mathrm{Kr}$ PLIF technique holds promise for making $\mathrm{Z}$ measurements even in sooting flames; however, it remained only qualitative since quenching corrections were not made to the $\mathrm{Kr}$ fluorescence signals.

The present study seeks to experimentally quantify $\mathrm{Z}$ and soot-volume fraction $\left(f_{\mathrm{v}}\right)$ fields, and kinematics in the near-field soot-inception region of a jet flame using simultaneous diagnostics including two-photon Kr PLIF, stereoscopic particle image velocimetry (sPIV) and LII. The flame of interest is a turbulent, non-premixed $\mathrm{C}_{2} \mathrm{H}_{4} / \mathrm{N}_{2} / \mathrm{Kr}$ jet flame at a jet Reynolds number of 8300 . From these measurements simultaneous planar fields of mixture fraction, temperature, three-component velocity and soot volume fraction are measured in the soot inception region to provide new information on the formation and transport of soot in a turbulent flame.

\section{Experimental approach}

Experiments were performed in a turbulent non-premixed jet flame that was surrounded by a co-flow of air. The co-flow was generated using a nozzle with a contraction area ratio of 2.8:1, and which had a $36 \times 36 \mathrm{~cm}^{2}$ exit area and a length of $76.2 \mathrm{~cm}$. The co-flow velocity $U_{\text {co }}$ was $0.7 \mathrm{~m} / \mathrm{s}$. The length of the jet delivery tube was $130 \mathrm{~cm}$ and the jet nozzle diameter, $d$ was $1 \mathrm{~cm}$. The bulk jet velocity was about $12.5 \mathrm{~m} / \mathrm{s}$. The Reynolds number at the jet flow exit was 8300 . The fuel mixture consists of $50 \% \mathrm{C}_{2} \mathrm{H}_{4}, 46 \% \mathrm{~N}_{2}$, and $4 \% \mathrm{Kr}$ by volume, giving a stoichiometric mixture fraction, $Z_{s t}=0.128$. The addition of $4 \% \mathrm{Kr}$ (by volume) was introduced in the fuel jet stream as the tracer for the PLIF measurements.

This study follows the approach of Hsu et al. [11] and the preliminary study of [3]. The fluorescence

of $\mathrm{Kr}$ is achieved by exciting the ground state $\left(4 \mathrm{p}^{61} \mathrm{~S}_{0}\right)$ to the $5 \mathrm{p}[3 / 2]_{2}$ state transition, a transition accessible via two-photon absorption at $214.7 \mathrm{~nm}$ [12]. The resulting fluorescence is collected at 
$760.2 \mathrm{~nm}$, arising from the decay of this upper state to the $5 \mathrm{~s}[3 / 2]_{2}$ state [12]. The natural lifetime of this fluorescence is $26.4 \pm 0.5 \mathrm{~ns}$ [13]. The $214.7 \mathrm{~nm}$ beam was produced by sum frequency generation method. The third harmonic $(355 \mathrm{~nm})$ of a Nd:YAG laser and output of a dye laser $(544 \mathrm{~nm})$ were combined in a Type I BBO crystal.

The $214.7 \mathrm{~nm}$ laser beam was focused with a $500 \mathrm{~mm}$ fused silica cylindrical lens into a small sheet of height $4 \mathrm{~mm}$ and thickness $250 \mu \mathrm{m}$. The small sheet height was used to maintain high laser intensity since the two-photon signal scales as intensity squared. The fluorescence was imaged through a $760 \mathrm{~nm}$ bandpass filter (10 $\mathrm{nm}$ bandpass) to reject unwanted radiation. The intensified camera was gated to $50 \mathrm{~ns}$. Note that the signal-to-noise ratio (SNR) is only sufficient over a small region near the peak of the laser sheet because the Kr PLIF signal is nonlinear; therefore, the data shown here were restricted to a height of only $1 \mathrm{~mm}$.

Both the fuel-jet and coflow were seeded with aluminum oxide $\left(\mathrm{Al}_{2} \mathrm{O}_{3}\right)$ particles of nominal diameter $0.5-1.0 \mu \mathrm{m}$ for PIV. The $\Delta t$ between the two PIV pulses was set to $32.5 \mu \mathrm{s}$. Two $2048 \mathrm{x} 2048$ pixels CCD cameras were used in a stereoscopic alignment to capture the 3-component PIV images. The cameras were fitted with $105 \mathrm{~mm}$ focal length lenses mounted to Scheimpflug mounts. Both PIV cameras were on the same side of the light sheet and the angle between two cameras was 60 degree. A $750 \mathrm{~mm}$ spherical lens and a negative focal length $(-60 \mathrm{~mm})$ cylindrical lens were used to form a sheet for both PIV and LII. The field of view is $3 \mathrm{~cm} \mathrm{x} 3 \mathrm{~cm}$ and spatially overlapped with the fields of view of the PLIF and LII measurements. LaVision DaVis 7.2 was used for spatial image mapping for PIV, LII, and PLIF measurements and to process PIV images. An iterative, multi-pass, adaptive interrogation windowing algorithm was used for PIV image processing. The final iteration was 32x32 pixels with a $75 \%$ overlap between adjacent interrogation windows. Vectors with a magnitude greater than 3 times the standard deviation of the neighboring vectors were defined as spurious vectors and were replaced with the median of the valid neighboring vectors. The first pulse of $532 \mathrm{~nm}$ light was used for LII 
measurements. The $532 \mathrm{~nm}$ laser fluence was $0.2 \mathrm{~J} / \mathrm{cm}^{2}$ and the pulse duration was about $10 \mathrm{~ns}$; therefore, the LII is in the plateau region. The laser pulse for the PLIF measurements was placed between the two PIV laser pulses, which was $10 \mu$ s after the first PIV laser pulse.

An intensified CCD camera with resolution of 512x512 pixels was used for LII. The soot incandescence was imaged through a bandpass filter with a central wavelength of $400 \mathrm{~nm}$ and bandwidth of $40 \mathrm{~nm}$ (FWHM). The intensified camera for LII was gated to $500 \mathrm{~ns}$. Both soot extinction and LII measurements of $\mathrm{C}_{2} \mathrm{H}_{4} /$ air premixed flat-flame using McKenna burner were performed by establishing various equivalence ratios of fuel-rich premixed flames to obtain the calibration constant for converting LII intensity counts to $f_{\mathrm{v}}$. Extinction measurements were performed using He-Ne laser at a wavelength of $632.8 \mathrm{~nm}$.

Time-averaged temperature measurements were carried out using an unsheathed fine diameter $(51 \mu \mathrm{m}$ wire diameter) of Type $\mathrm{R}(\mathrm{Pt}-\mathrm{Pt} / 13 \% \mathrm{Rh})$ thermocouple to compare with the $\mathrm{Kr} \mathrm{PLIF}$ measurements. The thermocouple measurements were performed independently from the laser-based measurements. Studies have been reported that catalytic effects in the non-premixed flames are expected to be small due to low radical concentration $[14,15]$. Measured temperatures were corrected for radiative heat losses (e.g., $[14,16])$.

The uncertainty in the velocity from the PIV measurement is due to the particle inertia, thermophoretic velocity induced by temperature gradients, calibration procedure, and PIV processing algorithm and it is estimated less than $0.2 \mathrm{~m} / \mathrm{s}$. For LII measurements, the minimum detectable soot volume fraction was $0.27 \mathrm{ppb}$. Uncertainties in soot volume fraction measurements were estimated at $16 \%$, mostly from the extinction measurements and the calibration process. Precision uncertainty in the Kr PLIF measurements were due primarily to shot noise and pulse-to-pulse variation in the intensity. The krypton concentrations were held low enough that no effects of stimulated emission could be discerned. The combined precision uncertainty is roughly $18 \%$ near the flame zone and $4 \%$ at the 
maximum $\mathrm{Kr}$ PLIF signal at $\mathrm{r} / \mathrm{d} \approx 0$. Uncertainties in the thermocouple measurements included flow conditions, temperature reading device accuracy, radiation correction, and standard deviation of several sets of measurements. Note that the temperature validation from thermocouple measurements was used to help assess the accuracy of the Kr PLIF-based temperature measurements.

\section{Methodology for Inferring Mixture Fraction and Temperature}

Mixture fraction and temperature are determined from the Kr PLIF signals and an assumed state relationship. The Kr PLIF signals cannot be directly mapped to mixture fraction because the signals are influenced by density variations and quenching effects, which are not known independently. However, if we start with an assumed state relationship, then it is possible to map from the Kr LIF signal (normalized by the jet exit value) to mixture fraction and temperature. The quenching effects are derived from the species mole fractions that are derived from the state relationship and quenching rates, which must be independently measured. In other words, we are assuming that $T=T(Z), S_{f} / S_{f m a x}=S_{f, K r} / S_{f, K r, r e f}(Z)$ and $Q=Q(Z)$, where $Z$ is mixture fraction, $T$ is temperature, $S_{f, K r}$ is the $\mathrm{Kr}$ fluorescence signal, $S_{f, K r, r e f}$ is the fluorescence signal measured at a known reference condition (e.g., jet exit), and

$Q$ is the fluorescence quenching rate. Since we can measure $S_{f, K r} / S_{f, K r, r e f}$ then using the state relationship we can map to all other variables. Our assumed state relationship is derived from a laminar strained diffusion flame calculation. Such a state relationship has been shown to be quite accurate in low Reynolds number flames by using Raman scattering [11].

The $1 \mathrm{D}$ opposed jet code developed by Kee et al. [17] was used to simulate non-premixed $\mathrm{C}_{2} \mathrm{H}_{4} / \mathrm{N}_{2} / \mathrm{Kr}_{\text {-air }}$ flames, where the fuel composition was $50 \% \mathrm{C}_{2} \mathrm{H}_{4}, 46 \% \mathrm{~N}_{2}$ and $4 \% \mathrm{Kr}$ by volume. USC Mech II [18] was used for the detailed kinetic mechanism. The simulation output provided the state relationship that enables us to map the measured $\mathrm{Kr}$ PLIF signal to $Z$ and $T$, provided the quenching cross sections are known. Transport parameters and thermodynamic data in polynomial form for $\mathrm{Kr}$ were taken from the literature (Refs. [19] and [20] 
respectively), and combined with USC Mech II transport data and thermodynamic data. The specific LennardJones parameters used were: potential well depth, $\varepsilon k_{\mathrm{B}}=190.00 \mathrm{~K}$ and collision diameter, $\sigma=3.61 \AA$. Binary diffusion coefficients of $\mathrm{Kr}$ were re-evaluated by comparing with different literature values [21] of Lennard-Jones parameters and the differences are negligible for temperature and species profiles. Multi-component transport coefficients and thermal diffusion were used in the simulation. The Lewis number effect by adding only $4 \%$ of $\mathrm{Kr}$ was negligible.

The resulting species mole fraction and temperature profiles were used to map the measured Kr PLIF signal to $T$ and $\mathrm{Z}$ by accounting for collisional quenching rates of major species. The total quenching rate is given by $Q=\sum_{i} q_{i} X_{i}$, where $q_{i}$ is the $\mathrm{Kr}$ quenching rate for collision partner $i$ and $X_{i}$ is the collision partner mole fraction. The collisional partners considered were $\mathrm{Kr}, \mathrm{N}_{2}, \mathrm{H}_{2}, \mathrm{CO}_{2}, \mathrm{CO}, \mathrm{O}_{2}, \mathrm{H}_{2} \mathrm{O}, \mathrm{CH}_{4}$, and $\mathrm{C}_{2} \mathrm{H}_{4}$. The temperature dependent quenching rates of $\mathrm{Kr}$ with collisional partners of $\mathrm{N}_{2}, \mathrm{H}_{2}, \mathrm{CO}_{2}, \mathrm{O}_{2}, \mathrm{H}_{2} \mathrm{O}$, and $\mathrm{CH}_{4}$ from Ref. [11] and quenching rates for $\mathrm{Kr}-\mathrm{Kr}$ and $\mathrm{Kr}-\mathrm{C}_{2} \mathrm{H}_{4}$ from Ref. [22] (see supplemental material -- Table S1). Details of the quenching rates measurements are described in Refs. [11] and [22].

\section{Results and discussion}

The Kr PLIF images were background subtracted and low-pass filtered with a $3 \times 3$ kernel to reduce the influence of noise. To make the krypton PLIF technique quantitative it is necessary to calibrate the fluorescence signal. The Kr fluorescence signal, $S_{f, K r}$ is given by

$$
S_{f, K r}=\eta_{c}\left(\frac{E_{l}}{a}\right)^{2} \frac{A_{21}}{\gamma} \frac{\hat{\sigma}^{(2)}}{4 \pi^{2}(\hbar \omega)^{2}} n_{K r} \int_{-\infty}^{\infty} F^{2}(t) d t
$$

where $\eta_{\mathrm{c}}$ is the collection efficiency of the detector system, $E_{l}$ is the pulse energy for the exciting radiation, $A_{21}$ is the spontaneous emission rate for the transition in question, $\gamma$ is the total decay rate of the excited state of krypton, $5 \mathrm{p}[3 / 2]_{2}, \hat{\sigma}^{(2)}$ is the effective two-photon absorption cross section, $n_{\mathrm{Kr}}$ is the 
krypton number density, $a$ is the exciting beam radius, $\omega$ is the frequency of the exciting radiation, and $F(\mathrm{t})$ is the temporal profile of the exciting radiation pulse. The fluorescence quantum yield is given by $A_{21} / \gamma$ where

$$
\gamma=A+\sum_{i} q_{i} X_{i}
$$

and $A$ is the spontaneous emission rate for all transitions.

We can show that $Z$ is related to ratios of several other variables:

$$
Z=\frac{S_{f, K r}}{S_{f, K r, r e f}} \frac{\gamma(Z, T)}{\gamma_{r e f}} \frac{T}{T_{r e f}} \frac{W_{f u e l}}{W_{m i x}(Z)} X_{K r, r e f}
$$

where $S_{f, K r}$ is $\mathrm{Kr}$ PLIF signal at the location of interest, $S_{f, K r, r e f}$ is $\mathrm{Kr}$ PLIF signal at the jet exit and $W$ is the molecular weight. In Eq. (3) "ref' refers to the value of the quantity in the fuel stream at the jet exit. The assumed state relationship allows us to create a mapping from the normalized PLIF signal to $Z, T$ and $X_{i}$

Figure 1 shows how the normalized $\mathrm{Kr}$ PLIF signal, temperature and $\mathrm{Kr}$ mole fraction vary with $\mathrm{Z}$. These results were obtained using the state relationship inferred from the 1D opposed-jet simulation and collisional quenching data of major species. Temperature and species mole fraction from the simulation were taken at the local strain rates, $K_{\text {local }}$ of $300 \mathrm{~s}^{-1}, 800 \mathrm{~s}^{-1}$ and $1000 \mathrm{~s}^{-1}$, and compared. $K_{\text {local }}$ was determined as the maximum velocity gradient along the center line just upstream of the flame in the opposed jet simulation. The Kr mole fraction and normalized Kr LIF signal did not vary with strain rate, but the temperature varied more significantly. These results show that the particular state relationship used will have relatively small effect on the $Z$ inferred from the $\mathrm{Kr}$ PLIF data, but about a $10 \%$ effect on the inferred temperature. At these strain rates we expect the state relationship to be valid instantaneously, and Fig. 1 shows the mapping is single-valued. In this study, temperature and $Z$ profiles were derived from a combination of the measured Kr PLIF and the state relationship based on the $800 \mathrm{~s}^{-1}$ 
strain rate. This strain rate was used because it is close to the actual strain rate measured near the reaction zone with PIV. In this near-field region $(x / d=10 d)$, the jet has not experienced significant mixing and so $Z$ remains relatively high on centerline (about 0.87). Note that both $Z$ and $T$ are derived from the normalized fluorescence signal (and the state relationship) and so the temperature field is not independent of $Z$.

The resulting LII intensity was mapped to $f_{\mathrm{v}}$ using the calibration constant $[23,24]$, obtained from LII/extinction measurements of $\mathrm{C}_{2} \mathrm{H}_{4} /$ air premixed flat-flames generated in a flat-flame McKenna burner. The choice of the complex refraction index, $m$ is critical for the accuracy of $f_{\mathrm{v}}$ measurement. A wide range of values for $m$ have been reported in the literature (e.g., [25-29]), and differences of a factor of 2 in $f_{v}$ [30] can be obtained by using $m$ between Refs. [25] and [29]. In this study, the Ref. [25] values were used $(\mathrm{m}=1.57-0.56 i)$, since they have been widely used in the literature.

Figure 2 shows simultaneously-acquired instantaneous $f_{\mathrm{v}}, Z$ and $T$ fields derived from $\mathrm{Kr}$ PLIF superimposed on the axial velocity field. Also shown is the stoichiometric velocity contour (white line), $U_{\text {stoic }}=\left(U_{0}-U_{c o}\right) Z_{s t}+U_{c o}(=2.2 \mathrm{~m} / \mathrm{s})$, which is known to correspond approximately with the location of the reaction zone [31], where, $U_{0}$ is the centerline velocity at the jet exit. $Z_{\mathrm{st}}(0.128)$ is shown as the red contour and $Z=0.3$ is shown as green. We see that the $U_{\text {stoic }}$ contour is just to the outside of $Z_{\text {st }}$ and $T_{\max }$. $f_{\mathrm{v}}$ tends to be found near the stoichiometric contour on the fuel-rich side and within the temperature band of about 1200-1600 K. This figure shows a soot structure with maximum soot volume fraction is $5.4 \mathrm{ppb}$ at $x / d=10$. The temperature peaks at $\mathrm{Z} \approx 0.17$ on the lean side of the reaction zone, and the peak soot volume fraction $f_{\mathrm{v}, \max }$ is near the $\mathrm{Z} \approx 0.35$, which is in the lower-temperature fuel-rich side of the reaction zone.

Figure 3a shows simultaneously-acquired instantaneous radial profiles of $\mathrm{Z}$ and axial velocity $U$. It is seen that $Z$ and $U$ have the same general shape, which is expected since they both have their peak value in the potential core and then reduce in value owing to mixing with the co-flow gas. The radial locations 
of $Z_{\text {st }}$ and $U_{\text {stoic }}$ at $10 d$ above the jet exit are marked in Fig. 3a. The profiles show that $Z_{\text {stoic }}$ and $U_{\text {stoic }}$ are nearly coincident, which is expected since $U_{\text {stoic }}$ has been shown to mark the approximate location of the reaction zone.

Figure $3 \mathrm{~b}$ and $3 \mathrm{c}$ shows simultaneously-acquired instantaneous radial profiles of $T, Z$, and $f_{\mathrm{v}}$ at the location of $10 d$ above the jet exit. The radial profiles are obtained from a single row of pixels in the images. We see that the elevated temperature regions tend to be much broader than the soot, which is expected from previous studies $[7,8]$. Although these profiles represent just a single instance, we see that the peak soot is associated with the rich side of the flame at a temperature of about $1200 \mathrm{~K}$ in Fig. $3 \mathrm{~b}$ and $1400 \mathrm{~K}$ in Fig. 3c. Additionally, we can see that the peak value of $f_{\mathrm{v}}$ occurs over the mixture fraction range $Z \approx 0.25$ to 0.5 , and $Z \approx 0.3$, respectively, as shown in Fig. $3 \mathrm{~b}$ and $3 \mathrm{c}$ (the red dashed lines mark $Z=0.3$ ). References 7 and 42 indicate that the soot is characterized by large positive growth over the range $0.25<Z<0.5$ and peaks at about $Z \approx 0.3$, which corresponds to the approximate peak in the soot precursor/growth species acetylene (and naphthalene) [5, 7, 32]. Note that the current opposed flow simulations of $50 \% \mathrm{C}_{2} \mathrm{H}_{4} / 46 \% \mathrm{~N}_{2} / 4 \% \mathrm{Kr}$-air flames also show that the peak mass fraction for acetylene $\left(\mathrm{C}_{2} \mathrm{H}_{2}\right)$ occurs at about $Z=0.3$.

Figure 4 shows mean temperature and $Z$ profiles derived from the measured $\mathrm{Kr}$ PLIF and state relationship based on the $800 \mathrm{~s}^{-1}$ strain rate using 1280 instantaneous images. For validation of the technique, mean temperature profiles of non-premixed $\mathrm{C}_{2} \mathrm{H}_{4} / \mathrm{N}_{2} / \mathrm{Kr}$ flames were also measured using fine-wire thermocouples to compare with Kr PLIF experimental results. A comparison of mean temperature profiles derived from Kr PLIF and measured by R-type thermocouples with $51 \mu \mathrm{m}$ wire diameter is shown in Fig. 4. The temperature values measured by the thermocouple were corrected for radiation effects [14]. It is well known (e.g., [14, 33, 34]) that thermocouple measurements can be affected by other sources of error such as conduction along the thermocouple wire and potential catalytic effects due to the presence of the bare thermocouple wire. In addition, when a thermocouple is inserted 
into a sooting flame, soot particles will deposit on the junction and both the junction diameter and its emissivity will increase. These parameters are important to obtain the flame temperature and so the error in the temperature measurement can be significantly increased by soot deposition. Nevertheless, procedures have been suggested that enable accurate thermocouple-based flame temperature measurements to be made in sooting flames $[14,33,34]$. In addition, there were no significant problems with soot deposition because the present measurements were made in regions of low soot concentration.

Figure 4 also shows the mean temperature profiles and mean $f_{\mathrm{v}}$ computed using the 1280 instantaneous images. Although the temperature and mixture fraction profiles from the PLIF showed symmetry along the radial direction, the shape of the mean soot volume fractions showed a slight asymmetry with greater soot concentrations on the left (laser entry) side. Asymmetric soot volume fraction profiles have been reported in several previous studies [24, 35]. Recent study by Nathan, Dally, and coworkers [36] suggested that beam steering can alter the distribution of local fluence in the laser beam sheet and thus cause this asymmetry, although we can observe asymmetry in the visible luminosity at the flame base, which does suggest there is a natural asymmetry in the soot formation. Soot is predominantly formed within the temperature band of $1100-1500 \mathrm{~K}$ on the fuel-rich side and peak $f_{\mathrm{v}}$ is formed between the temperature bands of 1300-1400 K. Previous work by others in pure $\mathrm{C}_{2} \mathrm{H}_{4}$ jet flames has shown that soot exists in the temperature range of $1200-1800 \mathrm{~K}$, with the peak $f_{\mathrm{v}}$ occurring in the temperature range of $1500-1600 \mathrm{~K}[37,38]$. The peak soot thus occurs at a higher temperature than found in this study, but this is not unexpected since pure ethylene has a higher flame temperature than the mixture $\left(50 \% \mathrm{C}_{2} \mathrm{H}_{4}\right)$ used in the current study. The mean temperature peak corresponds to $Z=0.16$, and peak $f_{\mathrm{v}}$ occurs at $Z \approx 0.4$.

Figure 5 shows the PDF of the streamwise velocity $U$ conditioned on the stoichiometric mixture fraction (specifically, the PDF of $U$ is compiled for the finite range $0.127<Z<0.129$ ). The PDF has a peak at just above $2 \mathrm{~m} / \mathrm{s}$, which shows that fluid at the stoichiometric mixture fraction has a preferential 
velocity that is near the stoichiometric velocity of $2.2 \mathrm{~m} / \mathrm{s}$ and is consistent with observations made from the instantaneous images.

Figure 6 shows joint PDFs between the mixture fraction and soot volume fraction (left panel) and between the temperature and soot volume fraction (right panel). The statistics were compiled from all pixels along a radial line at $x / d=10$. The figure shows that $f_{v}$ is found for values of $Z$ ranging from 0.15 to 0.65 , but the peak soot volume fraction is found over the more restricted range of $Z=0.3-0.4$. These observations are broadly similar to results of the DNS simulation of soot production in n-heptane flames [32], although in the simulation the soot seems to be more broadly distributed in mixture fraction space. The joint PDF involving temperature shows that $f_{v}$ is preferentially found over the range of temperature $1300 \sim 1500 \mathrm{~K}$ and peaks at $T \approx 1400 \mathrm{~K}$, which is consistent with the qualitative observations made above.

\section{Concluding remarks}

Simultaneous Kr PLIF, LII and PIV are used for the first time to obtain simultaneous measurements of mixture fraction, soot volume fraction and velocity in the soot inception region of an ethylene $/ \mathrm{N}_{2} / \mathrm{Kr}$-air jet flame. Mixture fraction is inferred from the normalized PLIF signal, a state relationship derived from a strained flame simulation, and quenching cross-sections obtained from the literature. The inferred mixture fraction fields enable the determination of the temperature, and possibly scalar dissipation and thermal dissipation fields if the signals are sufficiently high. For validation of the technique, PLIF-derived temperature profiles were compared to mean thermocouple measurements. The resulting radial profiles of temperature obtained from krypton PLIF and the thermocouple show excellent agreement. The data also showed that the stoichiometric velocity and stoichiometric mixture fraction are nearly coincident, the mean soot peaks in the expected range of temperatures, and the soot peaks at a mixture fraction of 0.3 , which is the location of peak soot precursors. 
Overall, results show that the Kr PLIF technique can be used to make quantitative mixture fraction and temperature measurements in the soot inception region, and can be successfully combined with LII and PIV. However, this technique is likely to be less applicable farther downstream or in heavily sooting flames where stronger fluorescence interference is expected and where radiation cooling renders the state relationship invalid. Future work will focus on improving the quality of the measurements and to derive additional statistical correlations among the soot volume fraction, mixture fraction, temperature and velocity.

\section{Acknowledgements}

This work was sponsored by the US National Science Foundation (CBET-1134020) and the Strategic Environmental Research Development Program (W912HQ-11-C-0035). 


\section{References}

[1] N.H. Qamar, Z.T. Alwahabi, Q.N. Chan, G.J. Nathan, D. Roekaerts, K.D. King, Combust.Flame 156 (2009) 1339-1347.

[2] V. Narayanaswamy, N.T. Clemens, Proceedings of the Combust. Inst. 34 (2013) 1455-1463.

[3] O.R.H. Buxton, R.A. Burns, N.T. Clemens, paper 2013-0479, 51st AIAA Aerospace Sciences Meeting including the New Horizons Forum and Aerospace Exposition, Dallas/Ft. Worth Region, Texas, 2013.

[4] P. Donde, V. Raman, M.E. Mueller, H. Pitsch, Proc.Combust.Inst. 34 (2013) 1183-1192.

[5] D.O. Lignell, J.H. Chen, P.J. Smith, T. Lu, C.K. Law, Combust. and Flame 151 (2007) 2-28.

[6] M.E. Mueller, V. Raman, Combust. Flame 161 (2014) 1842-1848.

[7] A. Attili, F. Bisetti, M.E. Mueller, H. Pitsch, Combust. and Flame 161 (2014) 1849-1865.

[8] S.M. Mahmoud, G.J. Nathan, P.R. Medwell, B.B. Dally, Z.T. Alwahabi, Proc.Combust. Inst. 35 (2015) 1931-1938.

[9] I.S. Burns, X. Mercier, M. Wartel, R.S.M. Chrystie, J. Hult, C.F. Kaminski, Proc.Combust. Inst. 33 (2011) 799-806.

[10] J. Zhang, R.W. Shaddix Cr Fau - Schefer, R.W. Schefer. Sci. Instrum. 82 (2011) 074101.

[11] A.G. Hsu, V. Narayanaswamy, N.T. Clemens, J.H. Frank, Proc.Combust. Inst. 33 (2011) 759-766.

[12] J.C. Miller, Phys. Rev. A, 40 (1989) 6969-6976.

[13] C.A. Whitehead, H. Pournasr, M.R. Bruce, H. Cai, J. Kohel, W.B. Layne, J.W. Keto, The J. Chem, Phys. 102 (1995) 1965-1980.

[14] C.S. McEnally, Ü.Ö. Köylü, L.D. Pfefferle, D.E. Rosner, Combust. Flame 109 (1997) 701-720.

[15] J.H. Miller, S. Elreedy, B. Ahvazi, F. Woldu, P. Hassanzadeh, Appl. Opt. 32 (1993) 6082-6089.

[16] K.C. Smyth, J.H. Miller, R.C. Dorfman, W.G. Mallard, R.J. Santoro, Combust. Flame 62 (1985) 157-181.

[17] R.J. Kee, J.A. Miller, G.H. Evans, G. Dixon-Lewis, Symposium (International) on Combustion 22 (1989) 1479-1494.

[18] X.Y. Hai Wang, Ameya V. Joshi, Scott G. Davis, Alexander Laskin, Fokion Egolfopoulos \& Chung K. Law, "USC Mech Version II. High Temperature combustion Reaction Model of $\mathrm{H}_{2} / \mathrm{CO} / \mathrm{C}_{1}-\mathrm{C}_{4}$ Compounds," (2007) http://ignis.usc.edu/Mechanisms/USC-Mech\%20II/USC_Mech\%20II.htm in, 2007.

[19] J.O. Hirschfelder, R.B. Bird, Molecular Theory of Gases and Liquids. John Wiley \& Sons, Inc., New York, 1954.

[20] B.R. A. Burcat, "Third Millennium Ideal Gas and Condensed Phase Thermochemical Database for combustion with updates from Active Thermochemical Tables," in, Technion and Argonne National Laboratory, 2005 mirrored at http://garfield.chem.elte.hu/Burcat/burcat.html.

[21] L.S. Tee, S. Gotoh, W.E. Stewart, Ind. \& Eng. Chem. Fundamen. 5 (1966) 356-363. 
[22] R.A. Burns, Development of Scalar and Velocity Imaging Diagnostics for Supersonic Hypermixing Strut Injector Flowfields, Chapter 2, Ph.D. Thesis, University of Texas at Austin, 2014.

[23] H. Bockhorn, H. Geitlinger, B. Jungfleisch, T. Lehre, A. Schon, T. Streibel, R. Suntz, Physical Chem. Chem. Phys. 4 (2002) 3780-3793.

[24] J. Zerbs, K.P. Geigle, O. Lammel, J. Hader, R. Stirn, R. Hadef, W. Meier, Appl. Phys. B, 96 (2009) 683-694.

[25] W.H. Dalzell, A.F. Sarofim, J. Heat Transfer, 91 (1969) 100-104.

[26] S.C. Lee, C.L. Tien, Symposium (International) on Combustion, 18 (1981) 1159-1166.

[27] H. Chang, T.T. Charalampopoulos, Proceedings of the Royal Society of London A: Mathematical, Physical and Engineering Sciences, 430 (1990) 577-591.

[28] J. Zhu, M.Y. Choi, G.W. Mulholland, S.L. Manzello, L.A. Gritzo, J. Suo-Anttila, Proc.Combust. Inst. 29 (2002) 2367-2374.

[29] T.C. Williams, C.R. Shaddix, K.A. Jensen, J.M. Suo-Anttila, Int.J. of Heat and Mass Transfer, 50 (2007) 1616-1630.

[30] J.B.J. K. Kohse-Höinghaus, Applied combustion diagnostics, Taylor and Francis, 2002.

[31] J.M. Donbar, J.F. Driscoll, C.D. Carter, Combust. Flame, 125 (2001) 1239-1257.

[32] F. Bisetti, G. Blanquart, M.E. Mueller, H. Pitsch, Combust. Flame 159 (2012) 317-335.

[33] J.H. kent, H.G. Wagner, Combust. Sci. Technol. 41 (1984) 245-269.

[34] R.J. Santoro, T.T. Yeh, J.J. Horvath, H.G. Semerjian, Combust. Sci. Technol. 53 (1987) 89-115.

[35] M. Köhler, K.P. Geigle, W. Meier, B.M. Crosland, K.A. Thomson, G.J. Smallwood, Appl. Phys. B, 104 (2011) 409-425.

[36] Z.W. Sun, Z.T. Alwahabi, D.H. Gu, S.M. Mahmoud, G.J. Nathan, B.B. Dally, Appl. Phys B, 119 (2015) 731-743.

[37] S.Y. Lee, S.R. Turns, R.J. Santoro, Combust. Flame 156 (2009) 2264-2275.

[38] A. Coppalle, D. Joyeux, Combust.Flame 96 (1994) 275-285. 


\section{Figure captions:}

Figure 1. Temperature (left axis), Kr PLIF signal normalized to the reference signal, and mole fraction of $\mathrm{Kr}$ times 25 (right axis) against mixture fraction. The state relationship was obtained using an OPPDIF simulation and collisional quenching rates for $50 \% \mathrm{C}_{2} \mathrm{H}_{4} / 46 \% \mathrm{~N}_{2} / 4 \% \mathrm{Kr}$ (by volume) nonpremixed flames at various strain rates. Solid line: $K_{\text {local }}=300 \mathrm{~s}^{-1}$; dashed line: $K_{\text {local }}=800 \mathrm{~s}^{-1}$; and dashed-dotted line: $K_{\text {local }}=1000 \mathrm{~s}^{-1}$.

Figure 2. Composite images showing a contour plot of the axial velocity component (U) with superimposed contours of soot volume fraction $\left(f_{v}\right)$ and (a) mixture fraction, and (b) temperature derived from the mixture fraction and state relationship. For the soot volume fraction plot the maximum contour is $5.4 \mathrm{ppb}$. For the mixture fraction plot a red contour is shown to highlight the stoichiometric mixture fraction, and a green contour is shown to highlight the mixture fraction where high levels of soot are present.

Figure 3. (a) Profiles of instantaneous $Z\left(Z_{s t}=0.128\right)$ and axial velocity $\left(U_{\text {stoic }}=2.2 \mathrm{~m} / \mathrm{s}\right)$, (b) and (c) Profiles of instantaneous temperature and soot volume fraction. Measurements are made at $10 \mathrm{~d}$ above the jet exit. Black dashed lines mark $\mathrm{Z}_{\mathrm{st}}=0.128$ in (a) and red dashed lines mark $\mathrm{Z}=0.3$ in (b) and (c).

Figure 4. Mean profiles of temperature (red line) and mixture fraction (blue line) derived from Kr PLIF, and normalized $f_{\mathrm{v}}$. Mean profiles were computed from 1280 instantaneous images at $10 d$ above the jet exit. For comparison, thermocouple-based temperature measurements are shown as the symbols.

Figure 5. PDF of axial velocity $U$ conditioned on $\mathrm{Z}_{\text {stoic }}(0.127<\mathrm{Z}<0.129)$.

Figure. 6. Joint PDFs between mixture fraction and soot volume fraction (left panel) and and between the temperature and soot volume fraction (right panel) along the radial line at at $x / d=10$. 


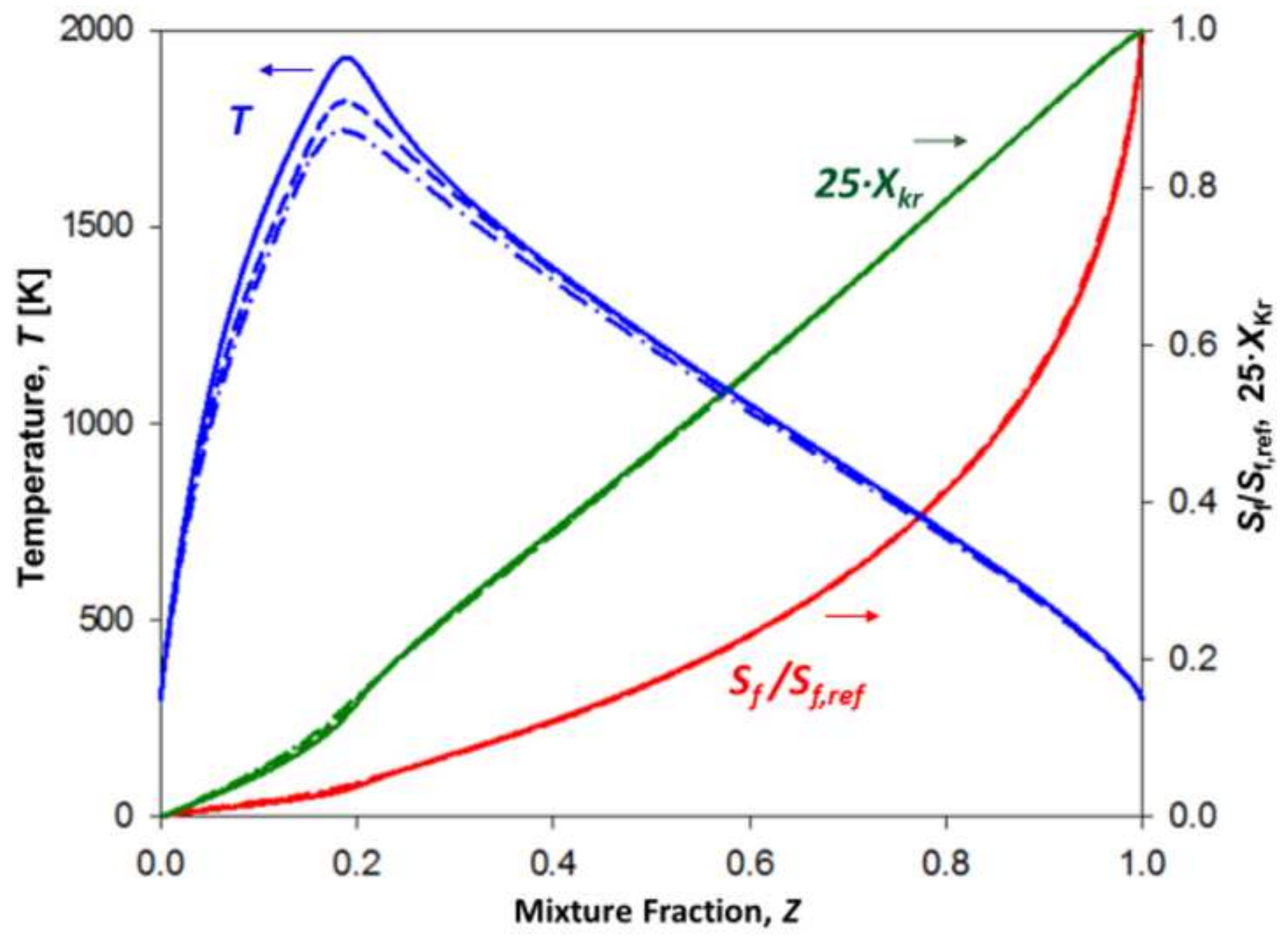




\section{(c) Muture trecton 2}

\section{(b) Funpecturatos}

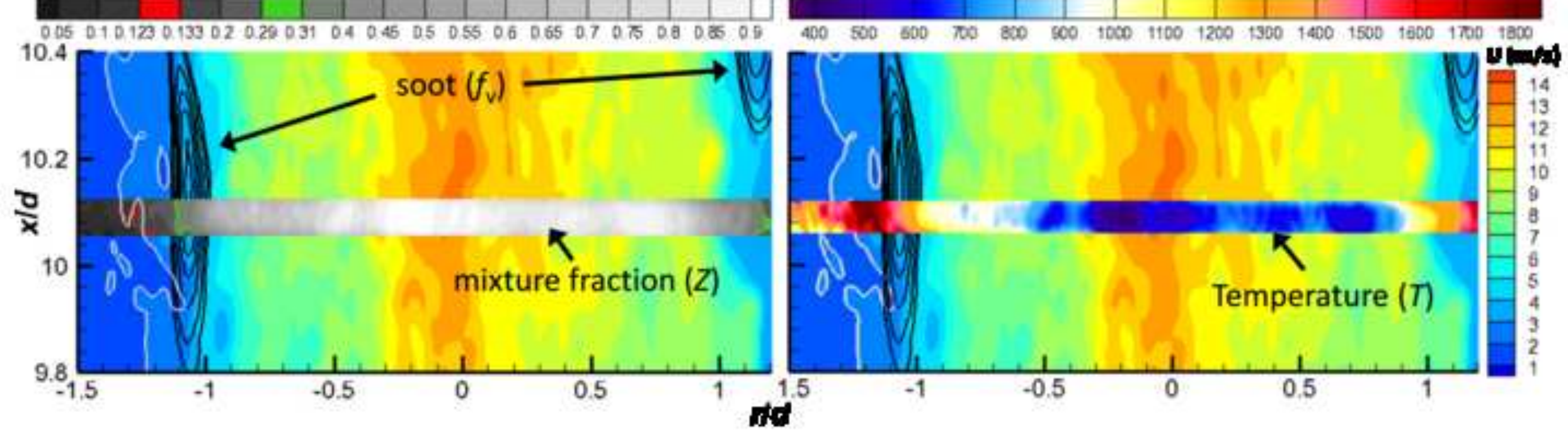


${ }^{\star}$ Figure 3

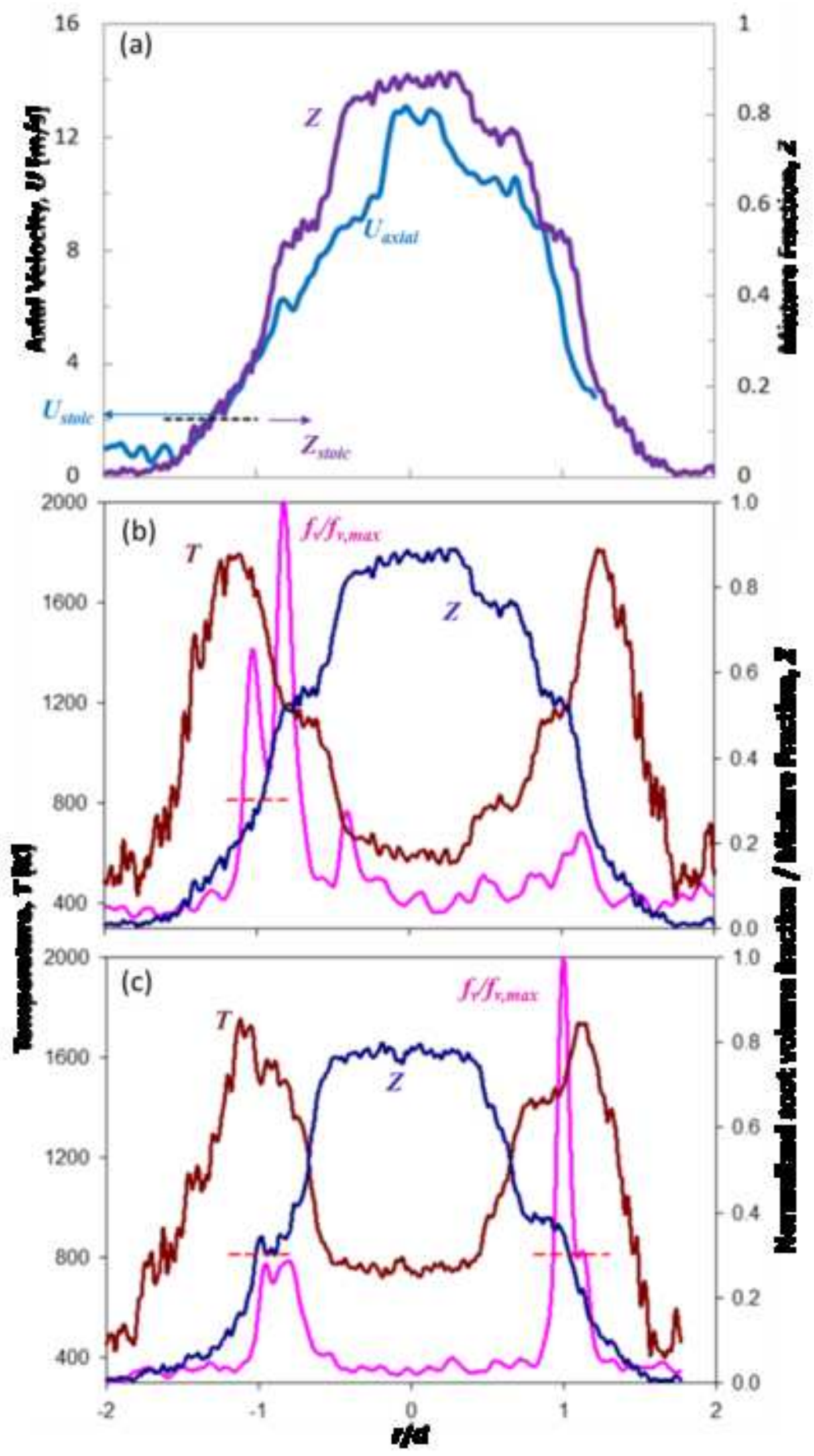




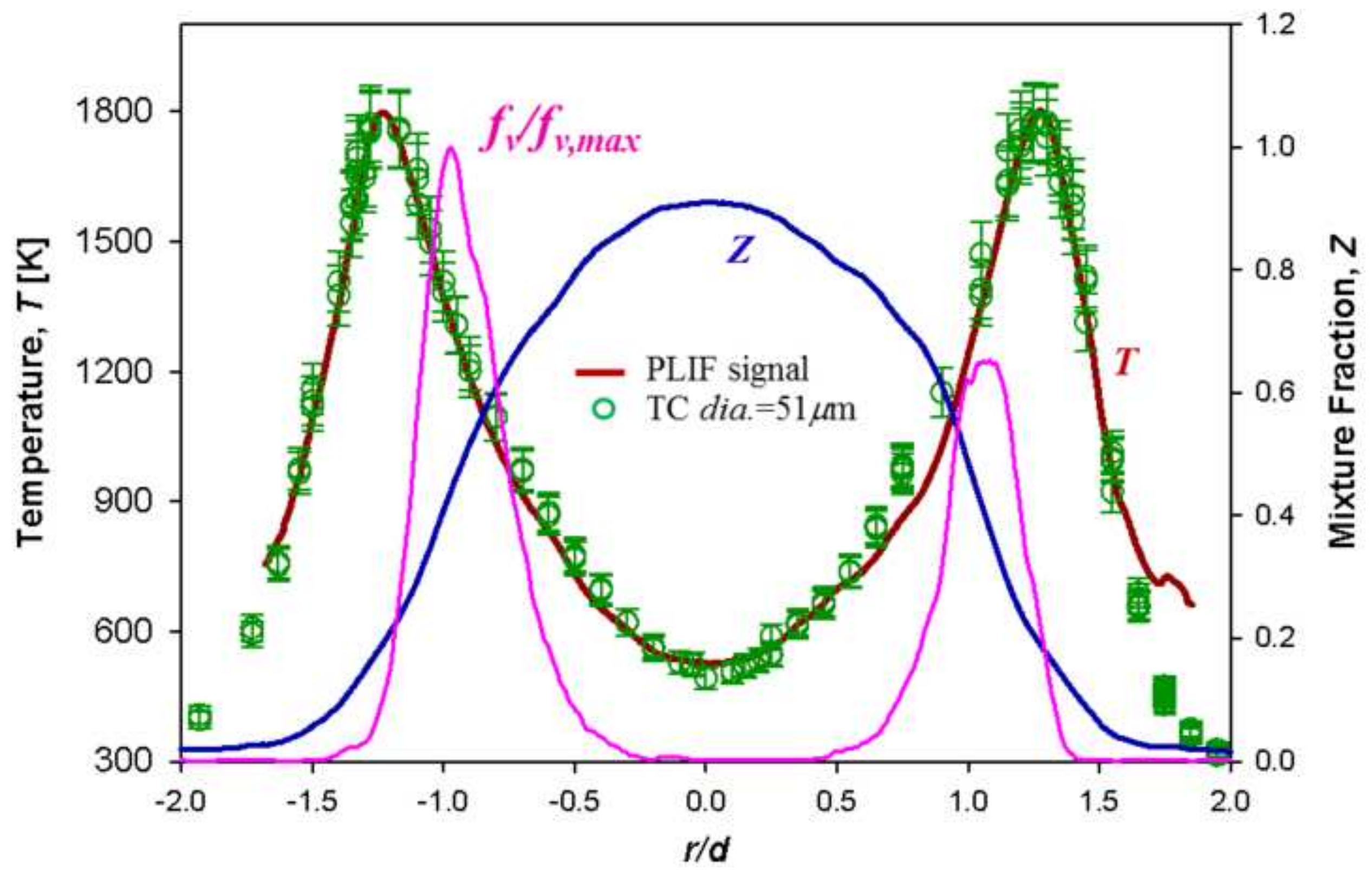




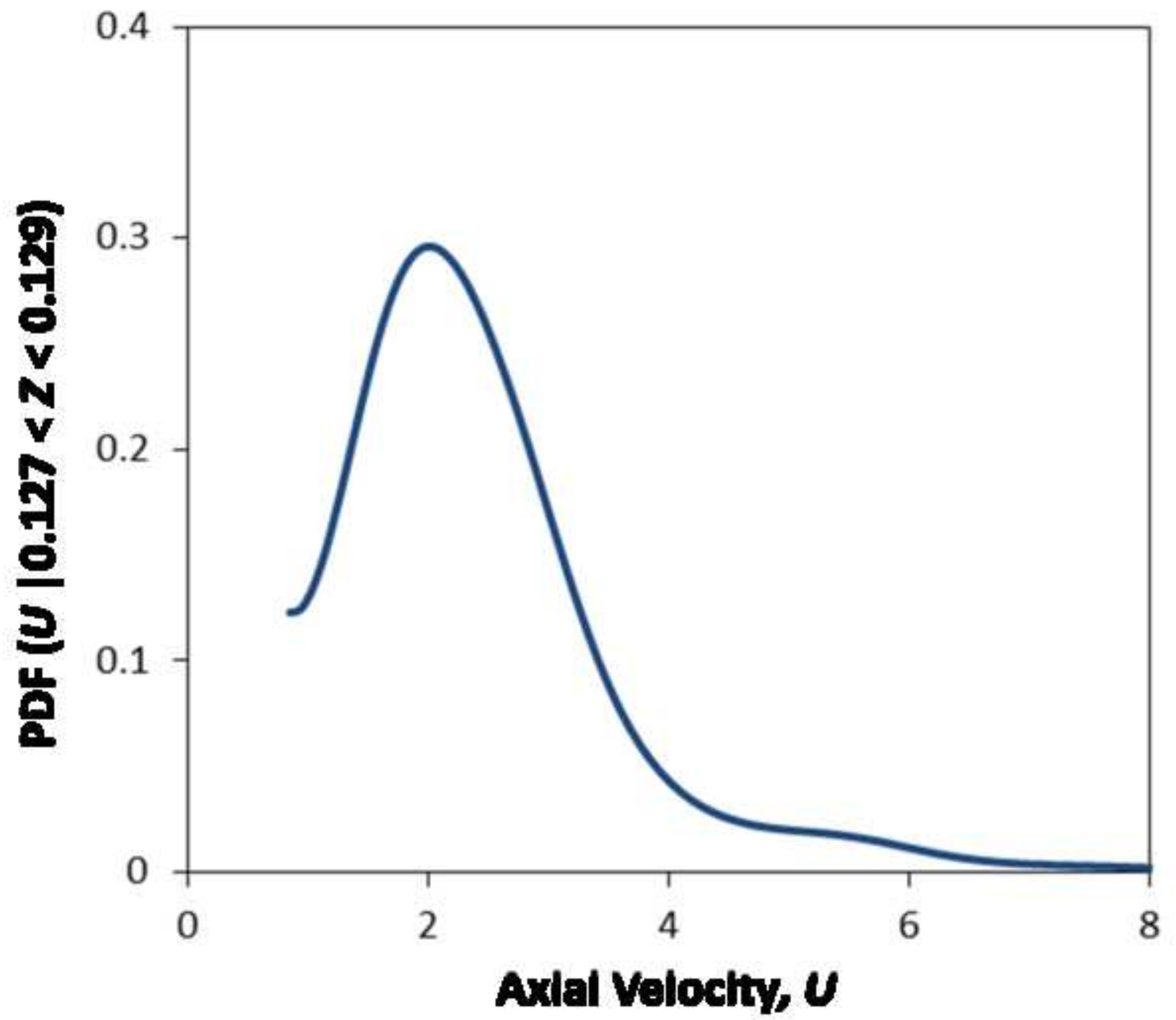



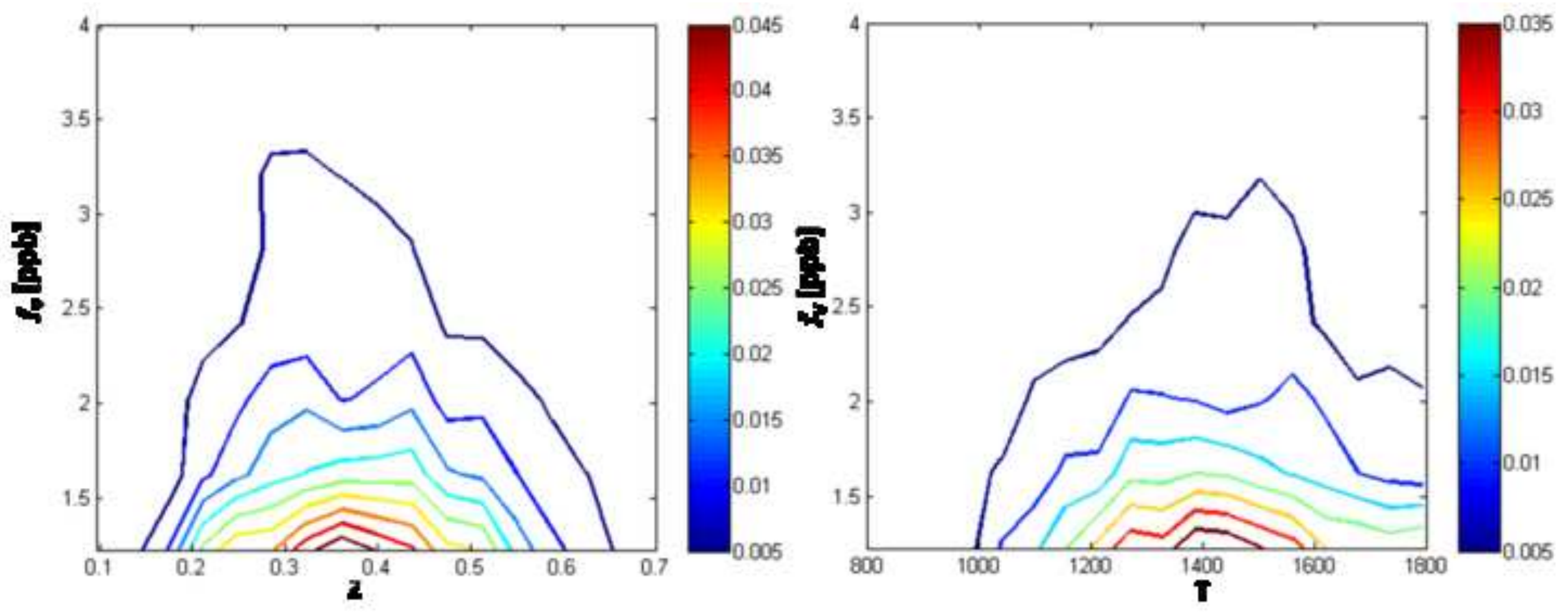